\title{
Social Isolation of Older Persons and Their Well Being: Case of Rwamucuucu Sub-County, Rukiga District, Uganda
}

\author{
Aharimpisya Dianah1, Banugire Firimooni Rweere ${ }^{2}$ \\ ${ }^{1}$ Nkumba University, Entebbe, Uganda \\ ${ }^{2}$ Bishop Stuart University, Mbarara, Uganda \\ Email: daharimpisya@nkumbauniversity.ac.ug
}

How to cite this paper: Dianah, A. and Rweere, B.F. (2019) Social Isolation of Older Persons and Their Well Being: Case of Rwamucuucu Sub-County, Rukiga District, Uganda. Open Journal of Social Sciences, 7, 1-14.

https://doi.org/10.4236/jss.2019.79001

Received: June 11, 2019

Accepted: August 29, 2019

Published: September 2, 2019

Copyright $\odot 2019$ by author(s) and Scientific Research Publishing Inc. This work is licensed under the Creative Commons Attribution International License (CC BY 4.0).

http://creativecommons.org/licenses/by/4.0/

\begin{abstract}
Older persons are vulnerable to poverty, social injustice, and isolation by their family, friends and communities. This essay explores the challenge of isolation and how it is connected to the other challenges and its effect on their wellbeing. We developed a conceptual framework that links isolation and other determinants of social wellbeing of old persons as a means of clarifying the right solutions to their problem. The focus was on older person's experiences of isolation and the causes of social isolation. The study was exploratory and descriptive, using the case of Rwamucuucu Sub County of the Rukiga District in 2013. We interviewed older persons and community members using questionnaire and focused group discussions, local leaders and officials with key informant interviews. The study found strong connections between social isolation and older person's wellbeing. The results show that older persons experience very many problems in their day to day lives including, poverty, lack of social support, ill health, abuse of human rights and mental problems, which have also led to increased isolation. Causes of social isolation of older persons were: family issues, poverty, ill-health, lack of right policies, ageism, cultural issues, modernism, illiteracy and poor planning lack of older persons organizations. The study recommended that while the duty to care of older persons lies with many stakeholders including the community, caretakers, civil society, and older persons themselves, government retains the lead responsibility to provide a positive living environment for older persons.
\end{abstract}

\section{Keywords}

Social Isolation, Well-Being, Older Persons, Basic Needs, Needs Satisfiers 


\section{Introduction}

Older persons are defined by the United Nations as those aged 60 years and above. In Uganda, older persons contribute immensely to social cohesion, support and care for children including HIV/AIDS orphans, conflict resolution, and act as guardians of traditions and cultural values, which are passed on from generation to generation in their communities and the nation as a whole. However, it is unfortunate that they are hindered by isolation and exclusion.

\subsection{Problem Statement}

The population of older persons aged 60 years and above has dramatically increased worldwide catching many governments much unprepared. In Uganda, the current population of older persons is estimated at 1.6 million (5\% of the population) and it is expected to increase to 5.5 million in 2050 [1]. This population increase has profound consequences at individual, community and national level.

The majority of older persons live in rural areas where poverty is rife, economic opportunities are limited, ill health is common and health services are inadequate. Older persons experience neglect of both their needs and potentials. Their ability to cope in conflict and emergencies is hampered by exclusion and lack of understanding of their special needs by communities, humanitarian and public agencies. They are often excluded in the design and management of emergency interventions and in social planning and programs to share their knowledge, values and life experiences as it was in the past.

According to Police records in Rwamucuucu Sub County, 5 (five) cases have been reported all indicating that older persons have been found dead due to the fact that there were heavy rains and since they were living alone, they did not get any rescue [2]. New PARA Social isolation of Older Persons and their wellbeing is not well documented and it is not clear how and to what extent it has led to segregation of older persons in almost every aspect of life hence increased rate of poverty levels, low standards of living, low self-esteem, self-denial, and depression.

Though there have been attempts to address the problems of the elderly contemplated in the Equal Opportunities Commission, National Policy for Older Persons, mass media, there is no evidence that these issues have been addressed especially in rural areas. It is therefore, against this that the researchers desired to understand the nature of the challenges of social isolation and its effects on the wellbeing of older persons specifically in Rwamucuucu Sub County in Rukiga District so as to establish possible ways of reducing this social ill.

\subsection{Study Objectives}

The overall objective was to find out the effect of social isolation on the wellbeing of older persons in Rwamucuucu Sub County.

1) To explore older person's experiences of social isolation 
2) To examine the causes of social isolation of older person

\section{Literature Review}

\subsection{Vulnerability of Older Persons}

Vulnerability is a term used to describe exposure to hazards and shocks. The level of vulnerability of older persons in Uganda is worrying. Poverty has become more acute among older persons and it is much more difficult for them to come out of it. Ill health and lack of health care, unsuitable residential areas, poor hygiene, diminishing family and community support, limited social security services, lack of education and training opportunities, limited employment and income generating opportunities, limited participation, and lack of balanced diet are some of the major factors contributing to the vulnerability of older persons.

\subsection{Focus on Isolation as a Priority}

Social isolation is the distancing of an individual, psychologically or physically, or both, from his or her network of desired or needed relationships with other persons. Therefore, social isolation is a loss of place within one's group(s) [3]. Absence of isolation is seen as important for a good quality of life [4]. Isolation among older adults is growing due to the high rate at which the general aging population is growing.

In the past, older persons in Uganda used to be treated with respect and love; they received care and support from their families, relatives and the community. Nowadays, it is vice versa. Rukiga being a rural area, has forced many young people do migrate to towns in search for jobs and better schools leaving the old people to fend for themselves. Older persons receive little or no care at all, their contributions are not really sought, their opportunity for making choices is restricted, and their life arena is shrinking.

\subsection{Social Well-Being}

This study was guided by the conceptual theory of social well-being to understand the personal and social well-being and isolation as a major determinant of the quality of life (well-being) of older persons.

Social well-being is a complex multilevel concept with three core elements as sub concepts that define its nature and scope as a theoretical tool for guiding social practice.

The first element comprises the four constituents of well-being namely: health of body and mind, utility or value of consumer goods and services used to satisfy the material needs of human beings, flourishing in society (family, community and wider social space) and psychological and spiritual fulfillment/contentment, often manifested as emotions of self-esteem and creativity. These are the essential characteristics of personal or social wellbeing which are indicators of quality of lives of people in any social setting. 
Human basic needs concept whose satisfaction brings about personal and social well-being. According to Maslow, there are four types of basic needs, material, social, socio-psychological and self-actualization basic needs as already mentioned above. However, this study is guided by Max-Neef's typology of basic needs which disaggregated the above four into nine basic needs with corresponding needs satisfiers. The basic needs satisfiers are the goods or services or attributes of institutions or behaviors or relationship that ensure needs of people are satisfied to the desired standard. The spaces in the economy or society where they are found are the sources of social well-being which must be targeted by social welfare policy and social workers as shown in Table 1, highlighting those that older persons cannot easily satisfy because of isolation.

The sources of social well-being concept which must be distinguished from the constituents that comprise the conditions or attributes of individual persons that generate the feel-good emotions of fulfillment/contentment with one's life in the community. These are the things that ensure good or bad quality of life. Therefore, social welfare/protection policy must aim at improving people's access to them. When the older persons are deprived of them, their wellbeing suffers and their quality of life is eroded to a state of suffering which may end in disability and death. Isolation is a major factor that denies old persons access to those sources of wellbeing and must be addressed by appropriate policies and practices of key stakeholders.

\subsection{Experiences of Social Isolation by Older Persons}

There is empirical evidence that the risk of becoming socially isolated is widespread among older persons. Social isolation deprives people of choices and opportunities to escape from poverty and denies them a voice to claim their rights. Therefore, the following are experiences of social isolation by older persons.

Table 1. Typologies of basic human needs: a conceptual framework.

\begin{tabular}{lccc}
\hline & Types of needs & A hierarchy of needs & Satisfiers \& sources of needs \\
\hline N. 1 & Subsistence & Material & Consumer goods and services \\
N. 2 & Protection T & Material/social & Consumer \& intermediate goods \\
N. 3 & Affection/love T & Material & Social relations (work and community \\
N. 4 & Understanding & Social & Learning activities/mechanisms \\
N. 5 & Participation T & Social & Social relations, property rights \\
N. 6 & Leisure/pest & Social & Social facilities/leaves/holidays \\
N. 7 & Creation T & Moral & Human rights/freedom \\
N. 8 & Identity/belonging T & Social/moral & Family, community \\
N. 9 & Freedom/Right T & Social /moral & Human rights/freedom \\
& Needs of being \& having, & Maslow's & Consumer goods and social relations, \\
\end{tabular}

Source: Adopted from [5]. Note: T denotes a basic need whose denial is a major cause of isolation of older persons and which must be addressed by service providers. 
Poverty: In Uganda, absolute poverty affects about $35 \%$ of the people and older persons are typically victims of poverty [6]. The Uganda Chronic Poverty Report of 2005 noted that older persons are among the more vulnerable groups, particularly widows with no assets, older persons living alone in remote rural areas. However, in most cases, poverty alleviation program exclude Older Persons, Micro finance organizations are reluctant to allow older persons borrow funds for income generating activities. Due to poverty, Older Persons in Uganda have very little or no income, shelter and security. This makes them vulnerable and open to abuse. Low incomes in Uganda make it hard for people to save for their elderly years. Many people enter their old years with limited assets and these are quickly exhausted as earnings reduce. Poverty has also made it harder for families to cope with the needs of Older Persons.

Participation: Older Persons in Uganda have made significant contributions to the development of the country. Even in their old age, they continue to contribute by being a reservoir of knowledge and cultural values, in addition to caring for their grandchildren and some members of their families. However, due to the increasing negative attitudes of the community and their weakening family institution, the contribution is often not recognized and their status in society not respected. As a result, they do not readily participate in community activities leading to loss of self-esteem, emotional and economic deprivation. These make them prone to psychosocial problems.

Social welfare: Traditional family structures have changed and Older Persons can no longer solely rely on the family for support. Existing Social welfare program covers Older Persons in the formal or public sector alone, while those in the informal or private sector are without any provision. The pension scheme and the National Social Security fund are centralized.

Food and Nutrition: Whereas research is ongoing in other countries and there has been sharing of information in sub-Sahara Africa [7], there has been limited research on this subject in Uganda. Older Persons find a problem of meeting their needs in areas of food and nutrition.

Ill health: The Study on Social Protection in Uganda (2002) asserts that ill health is a major source of worry and stress among older persons. Health of most Older Persons is often at stake. They suffer from all forms of ill health, which force them to withdraw from productive life rendering them dependent and disabled. Many older persons do not visit health centers due to long distances, poor mobility and negative attitudes towards older persons. There is limited availability of drugs in health centers and limited geriatric expertise. Traditional healers are often the alternative. Age-related diseases such as hypertension, stroke, diabetes, heart diseases, trachoma, cataract blindness and mental problems are some of the diseases affecting older persons in Uganda [8].

Water, sanitation and personal hygiene: Lack of water for Older Persons is a big problem especially in rural areas where there are long distances to safe water, older people resort to contaminated water. Even where pit latrines are available, 
they require agility to squat. A study conducted by [8] indicated that $42.8 \%$ of older persons use boreholes while the majority of older persons $59.2 \%$ use water from other sources. Persistent absence of adequate water results in poor personal hygiene and infrequent washing of clothes and bedding. Older persons who need assistance with personal care but are isolated can suffer from very poor personal hygiene.

Abuse of older persons' rights: There are frequent media reports in newspapers in Uganda of older women as victims of rape, of widows having their land and property grabbed by relatives as well as physical abuse following accusations of witchcraft. Negative beliefs about older persons still exist in villages. Older women are thought to cause the death of younger people. When an older person complains that, they are unwell or are suffering there is the belief that a young person will die. When many children die from an illness that is so complicated, the village can blame the older woman, destroy her home and then neglect her, hoping that she will move away or die and thus save the remaining children.

Gender inequalities: Most cultural practices dictate that women should not own property. Widows also tend to experience reduced social status. On the other hand, older men without a family may be more vulnerable than women who tend to have more domestic skills such as caring for family members who are sick. Older men who are unable to earn an income are seen as unproductive and their other support roles to the family may not be recognized.

Education, training and retraining: The majority of Older Persons have not attended formal education. At the same time, there is lack of training for the younger generations to appreciate that the ageing process is natural and that the aged are still useful members of the community with accumulated wealth of experience.

Lack of information: In Uganda, due to illiteracy, and the essence of alternative effective means of communication, the Functional Adult literacy program has not spread enough to give reading skills and where it has done so, there is not enough follow up of reading materials to enable them to acquire new life skills and the opportunity to read for leisure and further education. There is lack of information on the process of ageing to enable the community appreciate and reflect on the issues and the problems of the Older Persons.

HIV/AIDS pandemic: This continues to pose challenges to the Uganda society. This means that older persons are often carers of their own sick adult children and then orphaned grand children who require basic needs. Elderly men and women are still sexually active and stand a risk of contracting HIV/AIDS and transmitting it as well. Unfortunately, they are denied education and information on HIV/AIDS, yet it affects them as they take care of orphans, relatives and partners.

Housing: Most of older persons live in semi-permanent structures, grass thatched and mud walls. Some of the structures threaten to collapse anytime. 
Some are living in abandoned homes moving from one place to another. Older persons have homes without pit latrines, bathrooms, leaking roofs, and walls have gaping cracks.

Lack of income: Many older people do not have access to a regular income and sell any assets they have. They rely on casual laboring or selling foodstuffs with little cash reward. Social pension is limited to only the members who worked in the Government sector and accessing the pension can be difficult or unpredictable even for eligible older persons. The Social Assistance Grant for Empowerment (SAGE) given is too little to cater for all the needs of older persons and only 47 districts benefit [9].

Employment and Income security: Older persons find themselves vulnerable, discriminated against and denied employment opportunities once they reach or after retirement age. They are forced to retire to create room for younger people even when they still have so much to contribute. Most older persons in most cases are denied credit to help them invest for the future for instance a group of older persons in Kamuli District were refused to open an account in a bank because of their age and current micro-finance regulations say that everybody above 65 years is not allowed to get a loan.

Lack of family Care: In Uganda, the family is still the most important caring institution for older persons. However, socio-economic changes have weakened the strength of this system to provide adequately for its older persons. The situation has been aggravated by unemployment which has forced youths to migrate from to urban areas leaving older persons uncared for in the rural areas. In addition, society's negative attitude towards older persons is increasing due to associated costs of caring for them. As a result, older persons lack proper care and are very vulnerable to neglect, abuse and isolation [8].

\subsection{Causes of Social Isolation among Older Persons}

Many risk factors can lead to social isolation among older people including:-

Loss: Losses contributing to social isolation include: loss of health and function including hearing and other communication abilities, vision, mobility, and health generally; loss of relationships (loss of partner through death or divorce, loss of children when they leave home or through premature death, loss of grandchildren if the family moves away and loss of social networks).

Poor physical health: [10] found that poor health was the most important predictor of social isolation, followed by reduced social activity. Conversely, "social support and social network measures have been associated with improved health and well-being". However, the reverse is also of concern. That is, older people who are socially isolated are at increased risk of poor health [11].

Mental illness: A person who has a mental illness may suffer many of the losses listed above and may lose the confidence to make new friends or undertake new social activities. The issue of depression is very important and one that can be easily overlooked or misdiagnosed in primary health care. Depression 
and social isolation are closely linked [12] and in fact, it can be a circular problem. A person may become depressed, which then causes them to withdraw from family, friends, society and to become socially isolated which in turn leads to further depression.

Being a caregiver: Providing long-term, full-time care to a spouse or another family member, especially where there are few other informal supports available, can cause an older person to be socially isolated.

Communication: Lack of functional literacy may make accessing information difficult for some older people, thereby increasing their isolation.

Place of residence: Havens, 1989 noted that social isolation is closely associated with geographic location. Older people in rural and remote areas may be at risk of social isolation, particularly those who live at a distance from the town, no longer drive and whose families have moved away from the area.

Gender and/or marital status: In the study by [10] "Men were much more likely to be isolated than women". [13] also identified being male as a risk factor for social isolation. [14] notes that women's longer life expectancy often means an old age aggravated by financial problems and social isolation.

Community attitudes: Community attitudes towards older people can have a detrimental effect on the ability of these people to have satisfying, meaningful interactions within their community. "Negative attitudes towards older people and ageing, limit opportunities for older people to participate in the community". [15]

Transport: An inability to access transport can lead to social isolation and deterioration in general health and well-being [16]. Difficulty getting on and off public transport, resulting in loss of dignity, and poor design factors which impact on safety, such as lighting and steps, may result in older people not being willing to use public transport [17]. Limited mobility can lead to reduced life chances for social enjoyment, healthcare, participation in the community and participation in cultural activities.

\section{Research Method}

The study was exploratory and descriptive. Qualitative approach was used to capture people's views, attitudes and experiences of social isolation by Older Persons. An interview guide, questionnaire and focus group discussions were used to collect data. The sample size was 30 (thirty) respondents. It comprised of 10 (ten) older persons (FGD), 6 (six) older persons for personal life experiences (interview), 3 (three) community members, 3 (three) caretakers, 3 (three) opinion leaders, 3 (three) local leaders, 1 (one) CDO and 1 (one) sub-county chief. Random sampling was used to select the 16 older persons. Purposive sampling was used to select the key informants to ensure that various stakeholders in service delivery to the elderly had an input in the study. Data was categorized according to the similarity of responses given and then properly recorded, coded, edited, analyzed and different themes were developed. 


\section{Discussion of Study Findings}

This section discusses the findings about the experiences and causes of social isolation among older persons and how it affects their well-being.

\subsection{Social Isolation among Older Persons}

The findings revealed that there are different experiences of older persons. Poverty was identified as the major experience faced by older persons; abuse of human rights; ill health; lack of social support and/or belonging; and mental problems.

Poverty among older persons, to them it means, lack of income, inadequate access to basic needs of life and the burden of looking after orphans. The findings from study identified poverty as the major problem experienced by older persons in Rwamucuucu Sub County, and this clearly shows that poverty contributes to social isolation because people living in poor families are less likely to have positive experiences and they are less likely to participate in development activities. Older persons in this case, are likely to live at risk for all factors of social exclusion. From the interviews conducted, one respondent was quoted saying that:

"Because I am poor and old, I feel I am useless and can no longer produce anything good that anyone can ever recognize my living. I think it s better for me to leave this miserable world". (Tidwa, 82 years, Rwamucuucu Sub County).

Lack of social support which included feelings of loneliness, death of spouse and/or children and lack of security. This is evidenced by one respondent who said that she does not receive adequate care because she is a widow and her children died of HIV/AIDS. She narrates:

"Only God cares for me, protects me and gives me what to eat and cloth" (Tirwomwe, 79 years, Rwamucuucu Sub County).

This experience confirms the findings by [18] that regardless of how social isolation occurs; this is perceived as alienating or unpleasant, and the social isolation that occurs can lead to depression, loneliness, or other social and cognitive impairments that then exacerbate the isolation.

Abuse of their rights: this includes property grabbing, denied social security and protection (SAGE) and inadequate access to credit facilities. One respondent in the interviews revealed that his children were fighting for land and yet they do not want to work. Another respondent revealed that he was discriminated against in the government agricultural program (NAADs), because he was old and this made him feel he was detached from the programs that could help survive. Another respondent was quoted saying

"I feel so much excluded and think that I have no importance". (Tirwomwe, 79 years, Rwamucuucu Sub County).

These incidences sighted by the above respondents reveal that older persons' rights are abused and shows that many older people have been left behind and they suffer discrimination and isolation and are seen as outcasts. 
Ill health was also identified as a frequent experience in many older persons. This includes; body impairments, physical disability, and loss of energy to work due to many health complications. One respondent in interviews was quoted saying that:

"It takes a lot longer for me to do things than when I was younger" (Tirwomwe, 79 years, Rwamucuucu Sub County).

According to her, she can no longer work because her health can't allow since it is a combination of diabetes, hypertension, backache, and joint pains.

From the findings, mental issues were also identified experienced by many older persons including depression, eating disorders and low esteem. This is evidenced by [19] that older persons who are socially isolated and excluded from essential services or participating in aspects of everyday life are at high risk of mental health disorders such as depression, anxiety, past traumatic stress disorder and personality disorders.

\subsection{Causes of Social Isolation among Older Persons}

The strongest findings indicate that poverty, family problems and ill health were the major cause of social isolation. Other causes identified included; ageism; modernism; cultural issues; illiteracy; lack of strict policies on older persons; poor planning; and lack of older person's organizations.

Poverty was the major cause of isolation of older persons. As earlier noted in the literature review, poverty is one of the key factors that contribute to social isolation. This is true because in Uganda, absolute poverty affects about $35 \%$ of the people and older persons are typically victims of poverty [6]. [20] noted that older persons are among the more vulnerable groups, particularly older persons living alone in remote rural areas.

Family issues such as death of spouse, children or relatives, barrenness, withdrawal, children leaving home, low attachment with the family members, were the causes of isolation as identified by older persons and the key informants. For instance in FGD 2, older persons argued that when they have not produced or when their children and immediate relatives die, they lose security and they are left alone with no one to care about them and their properties are abused. These results conform to the findings of [21] that any weakening or diminishment of relationships or social roles might produce social isolation for individuals or their significant others. People who lose family, friends, and associated position and power are inclined to feelings of rejection, worthlessness, and loss of self-esteem. For example, one responded told the researcher that he feels lonely as if he has no relatives. He was quoted saying:

"I expect my relatives to be there for me at all times not leaving me with the houseboy".

"They left me to die alone as if they are strangers and it is like I don't have relatives".

"It really hurts me". Tidwa, 82 years, Rwamucuucu Sub County). 
Therefore, persons who live alone may also be without close supportive networks and such persons are more vulnerable to situational stress and to health problems than people who live with other members of their families ([22] $\mathrm{p}$. 564).

Multiple health challenges: As earlier noted, older persons are faced with many diseases, which deteriorate their lives all the time. Their health status makes them isolated and discriminated against due to different complications such as dementia and delirium that sometimes cause them to behave as young children and even have confusion most of the times. In the interviews conducted, two respondents revealed that their grandchildren feared them because of their skin that has rash, swollen feet and hands that are knobbed. Another respondent says:

"I have general body weakness, I cannot see clearly and hear very well, I have backache, hypertension, limb pain, and I feel pain all over the body".

He gets some treatment from the health unit, which is 3 kilometers from his home by the help of his neighbor though not always. He further says that sometimes the drugs given to him are too expensive and to make matters worse, the medical officer tells him to go and buy some drugs from town since they lack enough drugs.

According to [23], isolated older adults were shown to have increased risk of coronary heart disease and death related to congestive heart failure was predicted by social isolation.

\section{Conclusions}

Social isolation is a prevalent phenomenon and is greatly affecting older person's lives as the discussion has demonstrated. Unfortunately, while there is a renewed focus on the issues of older persons by policymakers, there is less academic focus on the unique characteristics and challenges of this segment of the human population. Older persons experience poverty, abuse of their rights, enormous health challenges, and a range of other social support needs as highlighted in the paper. These realities are especially common among older persons in rural areas who suffer from mental and psychological problems like dementia, depression, and low self-esteem. These problems are compounded by poverty and youth unemployment. The issue of youth unemployment has generated pressure onto the little wealth left for the older persons to survive on. Assets like land which the older persons hold in high esteem have increasingly become under attack by their own children and grandchildren who torment them to the extent of wishing them early death. This challenge is fueled by the fact that many older persons are illiterate and are many times duped by literate children to give away their little prized possessions. This is a departure from the traditional social support system where children and grandchildren were a form of social insurance to the elderly in the community.

Whereas the Government of Uganda is making interventions articulated in 
the National Policy for Older Persons [24], a lot needs to be done to address the plight of older persons especially in rural areas. The fact that majority older persons prefer to live the remaining part of their lives on earth in rural settings, academics and policymakers should put more attention on improving rural living conditions. Unfortunately, the available services for the older persons are concentrated in urban and semi-urban areas. Government health service policymakers need to rethink the health service delivery structure to attend to the unique health challenges of older persons. Under the current Ugandan government health service delivery system, older persons cannot get the medication for their unique health challenges at Health Centre II level which is the nearest service unit to the older persons in the rural setting. What is available for them at this level are pain killers yet their issues go beyond pain killing.

Whereas most researchers and policymakers point at the lack of enough resources to address the issues of older persons, this paper begs to differ. While it is undisputable that resources are never enough, in this case there appears to be a problem of prioritization of the needs of older persons. Policymakers seem to prefer to allocate more resources to the more vocal sections of the population like the youth, women, and children. Yet, comparatively, the numbers of older persons are much lower and therefore require fewer resources. If government for instance has the courage to declare expensive Universal Primary and Secondary Education programs, why is it difficult for it to institute a universal program for older persons? Instead, the Uganda government in its attempt to extend SAGE to all districts has raised the minimum eligibility age from 60 to 80 . This is a tendency toward exclusionary rather than inclusionary policymaking which is an undesired path. It appears as if the government is taking advantage of the vulnerability and voicelessness of older persons yet it is to ensure the wellbeing of all citizens including older persons.

While the duty to care of older persons lies with many stakeholders including the community, caretakers, civil society, and older persons themselves, government retains the lead responsibility to provide a positive living environment for older persons. As one of the older persons said, it is the united teeth that break a bone. Therefore the unity of different actors is important in the reversal of the growing trend of older persons' social isolation.

\section{Conflicts of Interest}

The authors declare no conflicts of interest regarding the publication of this paper.

\section{References}

[1] UBOS \& ICF International (2012) Uganda Demographic and Health Survey 2011. UBOS \& ICF International, Kampala.

[2] Aharimpisya, D. (2013) The Effect of Social Isolation on the Wellbeing of Older Persons in Rwamucuucu Sub County. Uganda Christian University, Kabale.

[3] Biordi, D.L. and Nicholson, N.R. (2009) Social Isolation. In: Chronic Illness. Impact 
and Interventions, 7th Edition, Jones and Bartlett Publishers, Sudbury, 85-116.

[4] Sinclair, et al. (1990) Social Isolation and Loneliness in Old Age: Review and Model Refinement.

[5] Max-Neet, M. (1993) Development and Human Needs: Latin America Crisis and Perplexity.

[6] Ministry of Finance, Planning and Economic Development (2004) Poverty Eradication Action Plan (2004-2007/8).

[7] World Health Organization (2001) Report on Nutrition of Older People. Dept. of Health Promotion. Health and Ageing.

[8] Ministry of Gender Labor and Social Development (2002) Study on the Health Needs of Older Persons. MGLSD, Kampala.

[9] UNICEF (2006) Social Protection Initiatives for Children, Women and Families. An Analysis of Recent Experiences. New York.

[10] Gardner, I., et al. (1998) Improving Social Networks: A Research Report. Lincoln Gerontology Centre, Adelaide.

[11] Hall, M. and Havens, B. (2001) The Effects of Social Isolation and Loneliness on the Health of Older Women. Research Bulletin, Centers of Excellence for Women's Health.

[12] Anderson, D.L. (2001) Treating Depression in Old Age: The Reasons to Be Positive. Age and Ageing, 30, 13-17. https://doi.org/10.1093/ageing/30.1.13

[13] Eldelbrock, D., et al. (2001) Characteristics of Social Support in a Community-Living Sample of Older People: The Sydney Older Persons Study. Australasian Journal of Ageing, 20, 173-178. https://doi.org/10.1111/j.1741-6612.2001.tb00382.x

[14] Kunugi (1989) Women and Population Aging.

[15] Queensland Department of Families, Youth and Community Care (1999) Families, Youth \& Community Care. State Government of Queensland.

[16] Department of Health and Ageing, Department of Health and Ageing (2000) Australia: Central Office, National Archives of Australia.

[17] Peel, C., et al. (2005) Assessing Mobility in Older Adults: The UAB Study of Aging Life-Space Assessment. Physical Therapy, 85, 1008-1019.

[18] Tilden, V. and Weinert, C. (1987) Social Support and the Chronically Ill Individual. Nursing Clinics of North America, 22, 613-620.

[19] Findlay, R. and Cartwright, C. (2002) Social Isolation and Older People: A Literature Review, Australasian Centre on Ageing. University of Queensland, Brisbane.

[20] Chronic Poverty Research Centre (2008) The Chronic Poverty Report (2008-09). Escaping Poverty Traps. Belmont Press Ltd., Northampton.

[21] Ravish (1985) Weakening Relationships/Social Roles.

[22] Compton, B.R. (1980) Family Care-Giving \& Impacts: Families Caring for and Aging America. Nation Academies Press, Washington DC.

[23] Brummet, B.H., et al. (2001) Characteristics of Socially Isolated Patients with Coronary Artery Disease Who Are at Elevated Risk for Mortality. Psychosomatic Medicine, 63, 267-272. https://doi.org/10.1097/00006842-200103000-00010

[24] Ministry of Gender Labor and Social Development (2009) National Policy for Older Persons: Ageing with Security and Dignity. MGLSD, Uganda. 


\section{SAMPLE OF QUESTIONS ASKED: FOCUS GROUP DISCUSSION GUIDE}

SECTION A:

Name of Parish

Sub-county

Number of participants.

Names (optional)

Age range of participants

Place of discussion

Time started

Time ended

Name of moderator

Name of note taker

Language (s)

\section{SECTION B}

1) Who are older persons?

2) What problems do older persons face because of their age?

3) Does traditional care of older people still exist? How?

4) What are the advantages of older styles of care versus modern styles for older persons?

5) Do older persons receive adequate care from the extended family?

6) What kind of care do they get?

7) What kind of diseases do older persons suffer from because of social isolaton?

8) Where do they get treatment?

9) Identify things that others are getting which older persons are not getting because of their age?

10) What is the source of livelihood of older persons?

11) Mention the organizations in your parish helping the elderly.

12) What are new methods that have been brought about by the government, NGOs or CSOs dealing with issues of the older persons?

13) How have these methods been helpful to the elderly?

14) Are older persons part of the development programs carried out by either for the government or Non-government (e.g. NAADS)?

15) What causes isolation of older persons?

16) What problems do older persons experience because of social isolation?

17) What could be the effects of social isolation on the wellbeing of the older persons?

18) What can be done in order to promote the wellbeing of older persons? 